\title{
Multiple paternity in Eucalyptus rameliana (Myrtaceae)
}

\author{
J ANE F. SAMPSON \\ Department of Botany, The University of Western Australia, Nedlands, Western Australia 6907
}

\begin{abstract}
Estimates of the level of multiple paternity/correlated outcrossing within and between fruits in a predominantly outbreeding population of the bird-pollinated mallee, Eucalyptus rameliana, were made using six allozyme loci. The correlation of outcrossed paternity $\left(r_{\mathrm{p}}\right)$ was positive and significant within fruits $(0.26)$ and the effective number of mates for a single fruit was estimated to be 3.85. This correlation was attributed to the low number of potential male parents and pollen-bearing flowers available at any one time in the population. Although consistent with suggestions that correlation of paternity may be a general feature of animal-pollinated plants, the level in E. rameliana was remarkably low considering its population size and phenology. There was no significant correlation of paternity between fruits, probably because flowers were pollinated at different times during the long season. Individual plants differed greatly in both male and female contributions to the next generation, with a small proportion of genotypes located in a small area contributing at least half of the gene pool of the seeds stored in the canopy. In contrast, the male contribution is probably from a wider area. The specialization of floral structure and phenology in E. rameliana for bird-pollination has probably contributed to correlation of paternity within fruits because there are fewer male parents available at any one time than in mass-flowering species. However, the behaviour of the bird pollinators also promotes pollen dispersal and multiplicity of paternity, factors which would be particularly significant when the female contribution to the gene pool is concentrated in a few plants.
\end{abstract}

Keywords: bird-pollination, correlated mating, Eucalyptus rameliana, mating system, multiple paternity, pollen dispersal.

\section{Introduction}

The mixed-mating model assumes that successive outcrossing events within a plant arise from independent samples of pollen from the total population of male plants. This assumption may be more appropriate for single-seeded wind-pollinated plants than for animal-pollinated plants, where deviations from random mating resulting from pollinator behaviour are likely (Schoen \& Clegg, 1984; Morgan \& Barrett, 1990).

Outcrossed progeny in multiseeded fruit may share the same male parent (correlation of paternity) if the pollen that gave rise to them, rather than being a random sample of the entire population, derives from one source and one pollination event

Correspondence. E-mail: jagwatts@cygnus.uwa.edu.au
(Brown et al., 1985), or if there is limited pollen carry-over (Ritland, 1989). Correlation of outcrossed paternity may also occur when the number of potential male parents is low or mating is mainly between near-neighbours (Surles et al., 1990), or if pollen is deposited as multiple grains such as pollinia or polyads (Schoen \& Clegg, 1984; Muona et al., 1991). Alternatively, multiplicity of paternity in a fruit can arise by deposition of one or more pollen loads from different male parents by a single pollinator (Marshall \& Ellstrand, 1985; Epperson \& Clegg, 1987), or from sequential visits by several pollinators each carrying pollen from different single sources, or carrying mixed pollen loads (Dudash \& Ritland, 1991).

Significant correlation of outcrossed paternal parentage has been found in several insect-pollinated species (Schoen \& Clegg, 1984; Brown et al., 
1986; Ritland, 1989; Morgan \& Barrett, 1990; Muona et al., 1991), which led Morgan \& Barrett (1990) to suggest that correlated matings may be a general feature of animal-pollinated plants. In Australia many plant species are pollinated predominantly by birds, and although there are several estimates of outcrossing for these species (Hopper \& Moran, 1981; Sampson et al., 1989, 1994, 1995, 1996; Coates \& Sokolowski, 1992), investigations of the correlation of mating in bird-pollinated species have not been made.

This study estimates the level of multiple paternity/correlated outcrossing within and between fruits in a predominantly outbreeding population of Eucalyptus rameliana $\mathrm{F}$. Muell. This species is pollinated by nomadic nectarivorous birds and correlated mating might arise in it because the flowers are multiovulate, populations are small and flower numbers are low. The estimates allow retrospective inference about pollen dispersal and the impact of bird-pollination on the mating system of this species.

\section{Materials and methods}

Eucalyptus rameliana is a long-lived eucalypt found in scattered populations of a few to several hundred individuals on the slopes and swales of red sand dunes in a restricted area of the Little Sandy Desert in Western Australia (Sampson et al., 1995). It has an open to bushy multistemmed growth form known as mallee, where stems are derived from an underground organ, the lignotuber. The lignotuber provides a source of dormant buds and food reserves so that plants may regenerate after fire (Pryor, 1976). Unlike most eucalypts, which have thousands of small flowers, E. rameliana plants have a few large, usually solitary, flowers that are borne on long peduncles, produce copious nectar and are pollinated primarily by nomadic nectarivorous birds.

Plants used in this study were from a single population of $\approx 200$ plants spread along about $0.6 \mathrm{~km}$ in the swale of a sand dune at lat. $24^{\circ} 12^{\prime} \mathrm{S}$ long. $120^{\circ} 26^{\prime} \mathrm{E}$. This population was known from a previous study to be highly outcrossed $\left(t_{\mathrm{m}}>0.90\right)$, whereas other populations had outcrossing rates as low as 0.54 (Sampson et al., 1995).

Plants within $50 \mathrm{~m}$ of two transects were mapped and the numbers of buds and fruits per plant counted. The distribution of plants in the swale was not continuous, so the beginning of transect 2 was $\approx 100 \mathrm{~m}$ north-east of transect 1 . Fruits for matingsystem analyses were collected in separate envelopes from all plants with more than two fruits. For each of 31 plants, progeny arrays of 33-39 seedlings from three to four fruits were assayed for six polymorphic loci from five enzyme systems by the procedures described in Sampson et al. (1995). These loci were known to have allele frequencies suitable for mating-system analyses.

Most models of mixed-mating systems assume that the progeny of a mother are a constant mix of halfsibs and selfs (Brown \& Allard, 1970; Clegg et al., 1978; Ritland, 1986) but this is not always the case. Ritland $(1988,1989)$ described mating events of the correlated selfing and paternity model using 'sibling pairs'. According to this model, if one samples two progeny from the same mother they can either be both selfs, one self and one outcross or both outcrosses. If outcrossing is not random then both outcrossed sibs can have either the same or different male parents. The proportion of full-sibs among outcrossed sibs is termed $r_{\mathrm{p}}$, the correlation of outcrossed paternity. There may also be an excess of both-selfed sibs over random expectations. This is termed $r_{\mathrm{s}}$, the correlation of selfing between two sibs.

Maximum likelihood estimates of parameters of the correlated selfing and paternity model were made using the method of Ritland $(1989,1990)$. The parameter $r_{\mathrm{s}}$ was constrained to zero as the selfing rate in the sampled population was known to be low $\left(t_{\mathrm{m}}>0.90\right)$ and practically no information on the correlation of selfing is obtained in such circumstances.

Correlated mating-system parameters were calculated for pairs of sibs sampled within and between fruits of E. rameliana. These parameters have high statistical variances when compared to estimates based on the mixed-mating model, but these can be reduced by obtaining minimum variance estimates over several independent diallelic or triallelic loci. Sampson et al. (1995) found no consistent significant association between the loci used in this study, using Burrow's composite measure of linkage disequilibrium $\left(\Delta_{i k}\right)$, as described in Weir (1990). Standard errors of estimates were obtained from 500 bootstraps.

\section{Results}

Plants in the sample population were just beginning to flower in May 1992. It was an abundant flowering season in the Little Sandy Desert but less than half the E. rameliana plants sampled had buds (41.4\%) and were therefore potential sources of pollen (Table 1, Fig. 1). There were also large differences in fecundity. For example, one plant produced $22.4 \%$ of the buds in 1992, but had no fruits. Over 
Table 1 Flowering and fecundity measures of Eucalyptus rameliana plants in the sample

\begin{tabular}{ll}
\hline Variable & \\
\hline Number of plants & 111 \\
Plants with buds in 1992 & 46 \\
Total number of buds & 1851 \\
Mean number of buds per flowering plant & $40.2(9.5)$ \\
Range of number of buds for flowering plants & $1-400$ \\
Number of plants with fruits & 46 \\
Total number of fruits & 1272 \\
Mean number of fruits per fecund plant & $27.6(8.0)$ \\
Range of number of fruits for fecund plants & $1-290$ \\
\hline
\end{tabular}

(1)
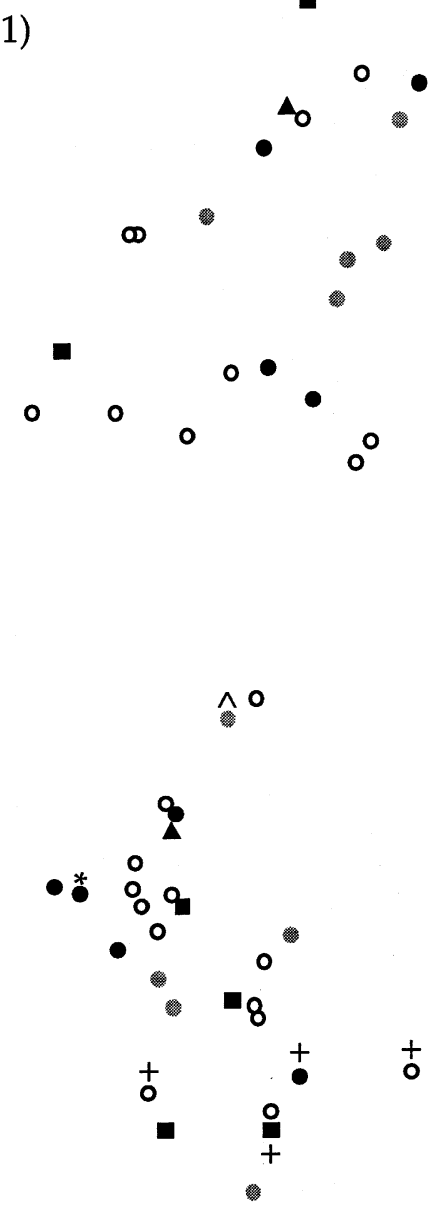

half $(53.5 \%)$ of the buds were produced by six plants, and $64.5 \%$ of the fruits on the 111 plants sampled came from five individuals and $81.4 \%$ from 10 plants (Fig. 1). Eighteen of the plants with buds had no fruits.

Plants with buds were distributed throughout the sample (Fig. 1) so that in some cases nearest-neighbours might both flower during the season although not necessarily at the same time. Some plants were up to $40 \mathrm{~m}$ from their nearest potential source of outcross pollen although again, because flowering may not be synchronous, this is a minimum distance.

The polymorphic loci used for estimation of mating-system parameters are shown in Table 2. All were triallelic but none had all three alleles at appreciable frequencies $(>0.1)$. Chi-squared values
(2)

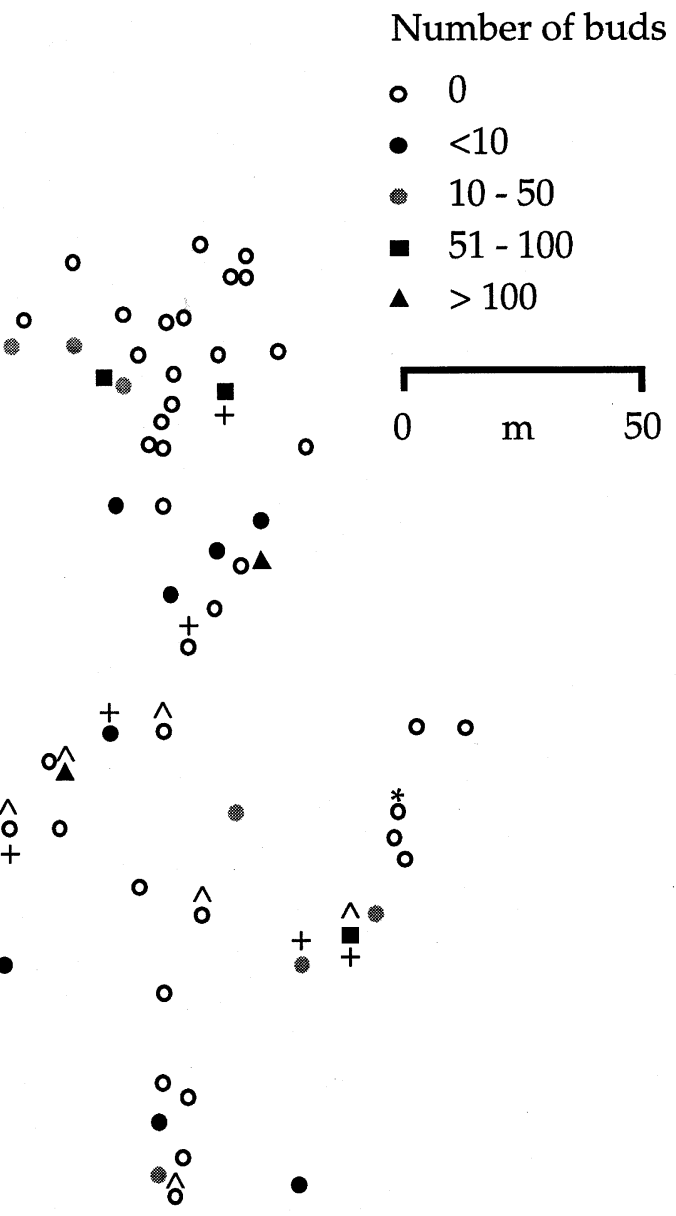

Fig. 1 Map showing the distribution of plants in the two transects used in the study of multiple paternity in Eucalyptus rameliana, and the number of buds on plants. *, Maternal genotype is $S d h 34 ;+, S d h 4$ allele found in progeny array; $\wedge,>50$ fruit. 
Table 2 Gene frequencies at allozyme loci and chi-squared goodness-of-fit tests between observed progeny segregation ratios and those expected under the assumptions of the correlated mating model for the sampled populations of Eucalyptus rameliana

\begin{tabular}{lcccc}
\hline Locus & $N$ & Allele & Frequency & $\chi^{2}$ \\
\hline Aat-1 & \multirow{2}{*}{1194} & 2 & 0.76 & 49.8 \\
& & 3 & 0.18 & \\
Aat-3 & \multirow{2}{*}{1194} & 4 & 0.06 & 78.1 \\
& & 2 & 0.08 & \\
Gpi-2 & \multirow{2}{*}{1154} & 3 & 0.78 & \\
& & 2 & 0.14 & 45.5 \\
Mdh-2 & \multirow{2}{*}{1207} & 4 & 0.82 & \\
& & 1 & 0.11 & \\
Pgd-1 & \multirow{2}{*}{1211} & 2 & 0.09 & 84.5 \\
& & 2 & 0.76 & \\
Sdh & \multirow{2}{*}{1219} & 5 & 0.15 & \\
& & 2 & 0.81 & 41.9 \\
& & 3 & 0.04 & \\
& & 4 & 0.09 & 34.01 \\
\hline
\end{tabular}

$N$, number of progeny surveyed.

of frequency tests based on fitting each locus separately to the model are also given in Table 2 . The tests are for progeny proportions $\left(\mathrm{H}_{\mathrm{o}}\right.$ : observed $=$ expected for each parental genotypic class). There are four d.f. for diallelic data but d.f. for triallelic data are difficult to determine (Ritland, 1989) and the chi-squareds are problematic. Ritland (pers. comm.) advises rank ordering the values and omitting 'outliers'. Although significant at 4 d.f., there were no outlying $\chi^{2}$ values and therefore none of the loci was excluded from the analyses.

The estimate of $t$ based on the correlated selfing and paternity model was 0.89 (SE 0.03) indicating predominant outcrossing (Table 3 ). It was slightly lower than the multilocus rate estimated for the same sample using the mixed-mating model $(t=0.93$, SE 0.03$)$ but this is to be expected as the former is a mean of single-locus estimates and less likely to identify all outcrossing events. There was no significant difference between single-locus and multilocus estimates of $t$ based on the mixed-mating model, indicating that most inbreeding was probably the result of self-pollination.

When sib-pairs were sampled from the same fruit, the correlation of outcrossed paternity was positive and significant $\left(r_{\mathrm{p}}=0.26\right)$, but when sampled from different fruits on the same plant, $r_{\mathrm{p}}$ dropped to 0.09
Table 3 Estimates of outcrossing rate and the proportion of outcrossed full-sib progeny, $r_{\mathrm{p}}$, averaged over loci, for pairs of progeny sampled within and between fruits on the same plant in a population of Eucalyptus rameliana.

Standard errors are based on 500 bootstraps and are given in parentheses

\begin{tabular}{ll}
\hline Variable & \\
\hline Outcrossing rate, $t$ & $0.89(0.03)$ \\
Correlated paternity, $r_{\mathrm{p}}$ & \\
$\quad$ Within fruits & $0.26(0.05)^{*}$ \\
Between fruits & $0.09(0.05)$ \\
\hline
\end{tabular}

*Significantly different from zero, $P<0.01$.

and was not significantly different from zero (Table 3).

\section{Discussion}

Estimates of the proportion of outcrossed full-sibs within fruits $\left(r_{\mathrm{p}}\right)$ have been made for only a few taxa, but cover a wide range of life forms and include $85 \%$ in the herbaceous legume Glycine argyrea (Brown, 1989), 37-44\% in the herbaceous annual/ perennial Mimulus guttatus (Ritland, 1989), 32\% in the emergent aquatic Eichhornia paniculata (Morgan \& Barrett, 1990), 35\% within a cluster in Acacia melanoxylon, where pollen is deposited as polyads (Muona et al., 1991), and in this study, 26\% in the arid zone mallee Eucalyptus rameliana. The estimate for E. rameliana is therefore the lowest made so far, using this method, but is consistent with the suggestion of Morgan \& Barrett (1990) that correlated matings may be a general feature of animal-pollinated plants.

The correlation of paternity within E. rameliana fruits could have arisen from a single deposit or by multiple deposits of pollen from a few sources, as large-flowered eucalypts are receptive for several days. In E. rhodantha, a closely related species with similar flowers, McNee (1995) observed that an individual pollinator might revisit a particular flower over several days. It seems likely that E. rameliana flowers would also be visited several times, as they secrete copious nectar over several days (S. D. Hopper, pers. comm.). In such circumstances, correlation of outcrossed paternity could arise because of limited pollen carry-over, mating mainly between near-neighbours or if the number of potential male parents was low.

It seems unlikely that pollen carry-over in $E$. rameliana would be low and the main source of the correlation of paternity found. Honeyeater bird 
pollinators of eucalypts tend to visit several flowers on a feeding bout before preening, and outcross pollination probably occurs on several flowers following an interplant movement (Hopper \& Moran, 1981).

Mating between near-neighbours could occur only if they had synchronized flowering which, because of its long, staggered flowering season, may not always be the case in E. rameliana. The distribution of a rare marker allele in the progeny arrays of sampled plants also suggests pollen is more widely dispersed than to nearest-neighbours (Fig. 1). Furthermore, honeyeaters usually move greater distances than between nearest-neighbours in other large-flowered eucalypts (Hopper \& Moran, 1981).

However, when one considers the low numbers of potential male parents and of pollen-bearing flowers in the population at any one time, it is not surprising that some seeds within E. rameliana fruit are fullsibs. Eighty-three plants $(41.4 \%)$ are estimated to have been capable of flowering in the entire population during the 1992 flowering season, but the number releasing pollen at any one time would be considerably less, because large-flowered eucalypts have staggered flowering over long seasons. In $E$. rhodantha for example, although most plants had buds, no more than $50 \%$ of plants were flowering at the peak of the season (Sampson et al., 1990). Indeed, some plants may finish flowering before others begin. The estimated size of this paternity pool is therefore at the low end of estimates summarized for trees by Levin (1988). With such a restricted effective population size, the correlation of paternity found within E. rameliana fruit seems remarkably low. In comparison, a higher level of correlation was found in Eichhornia paniculata, where the sampled population comprised 54 plants with many inflorescences per plant and 75-100 flowers per inflorescence (Morgan \& Barrett, 1990).

The likelihood of correlation of paternity within $E$. rameliana fruit would be reduced by the behaviour of bird pollinators, which promotes dispersal and multiplicity of paternity. Bird pollinators of large-flowered eucalypts may carry thousands of pollen grains on their bills and heads; they tend to visit fewer flowers per plant than are available, and on foraging bouts they tend to move greater distances than those between neighbouring trees. They also are involved in continuous aggressive interspecific and conspecific interactions (Paton \& Ford, 1977; Ford et al., 1979; Hopper \& Moran, 1981; McNee, 1995).

In contrast to the correlation of paternity within fruits, an insignificant proportion of sibs from different fruits shared the same pollen parent. Assuming that some of the correlation within fruits arose from multiple visits, one would expect some correlation between fruits if they were pollinated over the same period. Thus these flowers were probably pollinated at different times of the season or perhaps even different seasons, as eucalypts retain their fruit over several years. The latter possibility is less likely in this arid-zone species, where flowering is not annual, than in similar taxa from the more temperate south-west of Western Australia, where flowering occurs more regularly. The presence of several plants with fruit but no buds shows that plants do not flower consistently in every season. Staggered flowering within a season and differences between seasons would promote diversity of pollen parents represented in the seed stored in the plant's canopy.

The difference in the levels of correlation of paternity within and between fruits in E. rameliana represents an hierarchy of kinship and a situation where selective abortion of fruits rather than ovules within fruits would be a more effective mode of selection (Schoen, 1985; Ritland, 1989). Such a pattern would be consistent with the suggestion of James \& Kennington (1993) and Sampson et al. (1995) that postzygotic seed selection mechanisms operating within fruits of mass-flowering eucalypts would not be found in large-fruited, low-flowering intensity species.

Individual plants differed greatly in their contributions to the next generation in both male and female fertility, with a small proportion of genotypes located in a small area contributing at least half of the gene pool of the seeds stored in the canopy. In contrast, the male contribution is probably from a wider area, as flowering plants are distributed throughout the population and birds can move over great distances. Brown et al. (1985) pointed out that if one or a few plants provide most of the ovules or pollen in seed production, the progeny generation is subject to biased gene frequencies and elevated levels of inbreeding. In such cases, the degree of inbreeding arising from such biases may be greater than that caused by the self-fertilized component of predominately outcrossed species such as E. rameliana and needs to be taken into account in seedcollection strategies for conservation.

The differences in fecundity and concentration of the most fecund plants in a small area probably has an ecological rather than a genetic basis, as there was no evidence of clustering of genetically similar plants in this population. However, water availability would differ throughout the population because of 
differences in the levels of subsurface sandstone, and it seems likely that the most fecund plants are concentrated where the water table is nearer the surface.

Ritland (1989) showed how if certain assumptions were made, estimates of correlated mating could be used to make retrospective inferences about the mating pool of plants. For example, if there are $n$ mates and each has an equal probability of being the male parent, and if consecutive matings are independent (involve separate visits by pollinators), then the probability of outcrossing twice to the same mate is $1 / n$. Thus the effective number of mates is ${ }^{1} / r_{\mathrm{p}}$. From Table 3, the effective number of mates for a single fruit in E. rameliana is 3.85 . The specialization of floral structure and phenology in E. rameliana for bird-pollination has probably contributed to correlation of paternity within fruits, because there are fewer male parents available at any one time than in mass-flowering species. However, although $26 \%$ of outcrossed seeds within a fruit share the same male parent, $74 \%$ do not. As the outcrossing rate is 0.89 , this represents $66 \%$ of the total seeds within fruit. When more than one fruit is considered, almost all the outcrossed seeds have different male parents. The diversity of pollen parents represented in the canopy of $E$. rameliana is thus surprisingly high, considering the limitations of its population size.

The pollination and flowering strategy of $E$. rameliana promotes pollen dispersal, which increases the effective population size and reduces inbreeding, factors which could be particularly significant when the female contribution to the gene pool is concentrated in a few plants in a small area. Pollen dispersal retards the subdivision of populations caused by selection and drift. This, together with gene flow, acts as a cohesive force in the genetic system of the small, dissected populations of this species, which are characterized by low differentiation of moderately diverse populations (Sampson et al., 1995). Thus, this study illustrates how retrospective investigation of the mating system can be used to infer how the pollination system affects gene dispersal and the genetic structure of populations.

\section{Acknow ledgements}

I am grateful to Steve Hopper for the opportunity to study E. rameliana and for discussions on its pollination biology, Nick Foote, Steve van Leeuwen, Andrew Brown, Bob Bromilow and the Western Australian Department of Conservation and Land Management for field assistance, Rachel Phillips for technical assistance, and Spencer Barrett, Helen
Stace and Andrew Young for comments on the manuscript. This research was conducted while J.F.S. was an ARC Postdoctoral Research Fellow at The University of Western Australia.

\section{References}

BROWN, A. H. D. 1989. Genetic characterisation of plant mating systems. In: Brown, A. H. D., Clegg, M. T., Kahler, A. L. and Weir, B. S. (eds) Plant Population Genetics, Breeding, and Genetic Resources, pp. 145-162. Sinauer, Sunderland, MA.

BROWN, A. H. D. AND ALLARD, R. W. 1970. Estimation of the mating system in open-pollinated maize populations using isozyme polymorphisms. Genetics, 66, 133-145.

BROWN, A. H. D., BARRETT, S. C. H. AND MORAN, G. F. 1985. Mating system estimation in forest trees: models, methods and meanings. In: Gregorius, H. R. (ed.) Population Genetics of Forestry. Lecture Notes in Biomathematics, vol. 60, pp. 32-49. Springer-Verlag, Berlin.

BROWN, A. H. D., GRANT, J. E. AND PULLEN, R. 1986. Outcrossing and paternity in Glycine argyrea by paired fruit analysis. Biol. J. Linn. Soc., 29, 283-294.

CleGG, M. T., KAHLER, A. L. AND ALLARD, R. W. 1978. Estimation of life cycle components of selection in an experimental plant population. Genetics, 89, 765-792.

COATES, D. J. AND SOKOLOWSKI, R. E. S. 1992. The mating system and patterns of genetic variation in Banksia cuneata A. S. George (Proteaceae). Heredity, 69, 11-20.

DUDASH, M. R. AND RITLAND, K. 1991. Multiple paternity and self-fertilization in relation to floral age in Mimulus guttatus (Scrophulariaceae). Am. J. Bot., 78, 1746-1753.

EPPERSON, B. K. AND CLEGG, M. T. 1987. First-pollination primacy and pollen selection in the morning glory, Ipomoea purpurea. Heredity, 58, 5-14.

FORD, H. A., PATON, D. C. AND FORDE, N. 1979. Birds as pollinators of Australian plants. N. Z. J. Bot., 17, 509-519.

HOPPER, S. D. AND MORAN, G. F. 1981. Bird pollination and the mating system of Eucalyptus stoatei. Aust. J. Bot., 29, $625-638$.

JAMES, S. H. AND KENNINGTON, w. J. 1993. Selection against homozygotes and resource allocation in the mating system of Eucalyptus camaldulensis Dehnh. Aust. J. Bot., 41, 381-391.

LEVIN, D. A. 1988. The paternity pool of plants. Am. Nat., 132, 309-317.

MARShall, D. L. AND Ellstrand, N. C. 1985. Proximal causes of multiple paternity in wild radish, Raphanus sativus. Am. Nat., 127, 596-605.

McNeE, S. A. 1995. The Pollination Biology of a Rare Eucalypt Species, Eucalyptus rhodantha. M.Sc. Thesis, Curtin University of Technology, Western Australia.

MORGAN, M. T. AND BARRETT, s. C. H. 1990. Outcrossing rates and correlated mating within a population of Eichhornia paniculata (Pontederiaceae). Heredity, 64, 271-280.

(c) The Genetical Society of Great Britain, Heredity, 81, 349-355. 
MUONA, O., MORAN, G. AND BELL, J. C. 1991. Hierarchical patterns of correlated mating in Acacia melanoxylon. Genetics, 127, 619-626.

PATON, D. C. AND FORD, H. A. 1977. Pollination by birds of native plants in South Australia. Emu, 77, 73-85.

PRYOR, L. D. 1976. The Biology of the Eucalypts. Edward Arnold, London.

RITLAND, K. 1986. Joint maximum likelihood estimation of genetic and mating structure using open-pollinated progenies. Biometrics, 42, 25-43.

RITLAND, K. 1988. The genetic-mating structure of subdivided populations. II. Correlated mating models. Theor. Pop. Biol., 34, 320-346.

RITLAND, K. 1989. Genetic differentiation, diversity and inbreeding in the mountain monkeyflower (Mimulus caespitosus) of the Washington Cascades. Can. J. Bot., 67, 2017-2024.

RITLAND, K. 1990. A series of FORTRAN computer programs for estimating plant mating systems. J. Hered., 81, 235-237.

SAMPSON, J. F., HOPPER, S. D. AND JAMES, S. H. 1989. The mating system and population genetic structure in a bird-pollinated mallee, Eucalyptus rhodantha. Heredity, 63, 383-393.

SAMPSON, J. F., HOPPER, S. D. AND JAMES, S. H. 1990. Temporal variation in allele frequencies in the pollen pool of Eucalyptus rhodantha. Heredity, 65, 189-199.
SAMPSON, J. F., COllins, B. G. AND COATES, D. J. 1994. Mixed mating in Banksia brownii Baxter ex R. Br. (Proteaceae). Aust. J. Bot., 42, 103-111.

SAMPSON, J. F., HOPPER, S. D. AND JAMES, S. H. 1995. The mating system and genetic diversity of the Australian arid zone mallee, Eucalyptus rameliana. Aust. J. Bot., 43, 461-474.

SAMPSON, J. F., COATES, D. AND VAN LEEUWEN, S. 1996. Mating system in animal-pollinated rare and endangered plant populations in Western Australia. In: Hopper, S. D., Chapill, J. and Harvey, M. (eds) Gondwanan Heritage. Past, Present and Future of the Western Australian Biota, pp. 187-195. Surrey Beatty and Sons, Chipping Norton, Australia.

SCHOEN, D. J. 1985. Correlation between classes of mating events in two experimental plant populations. Heredity, 55, 381-385.

SCHOEN, D. S. AND CLEGG, M. T. 1984. Estimation of mating system parameters when outcrossing events are correlated. Proc. Natl. Acad. Sci. U.S.A., 81, 5258-5262.

SURLES, S. E., ARNOLD, J., SCHNABEL, A., HAMRICK, J. L. AND BONGARTEN, B. C. 1990. Genetic relatedness in openpollinated families of two leguminous tree species Robinia pseudoacacia L. and Gleditsia tricanthos L. Theor. Appl. Genet., 80, 49-56.

WEIR, B. S. 1990. Genetic Data Analysis. Sinauer, Sunderland, MA. 